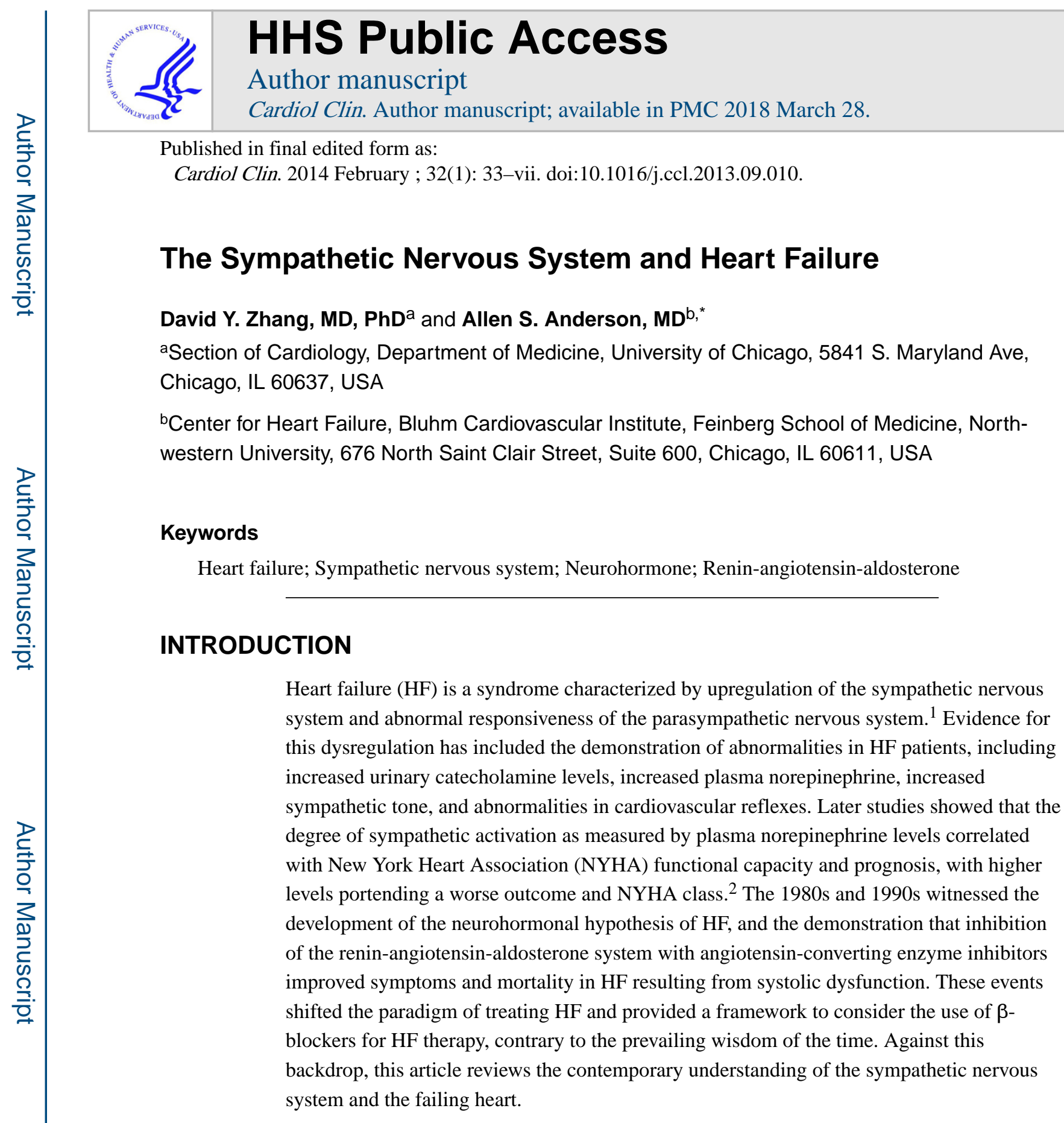

\title{
THE AUTONOMIC NERVOUS SYSTEM AND THE HEART
}

The sympathetic nervous system (SNS) has a wide variety of cardiovascular effects, including heart-rate acceleration, increased cardiac contractility, reduced venous capacitance, and peripheral vasoconstriction. ${ }^{1,3}$ Conversely, the parasympathetic nervous system affects the cardiovascular system by slowing the heart rate through vagal innervation. 4

*Corresponding author. aanderso@nmff.org.

The authors have nothing to disclose. 
Anatomy

Cardiac sympathetic nerve fibers travel along coronary arteries at the subepicardial level, predominantly in the ventricles. ${ }^{3}$ The cardiac parasympathetic nerve fibers run with the vagal nerve subendocardially after crossing the atrioventricular groove, and are abundant mainly in atrial myocardium and less so in the ventricle myocardium. ${ }^{5}$

\section{Physiology}

Four categories of the physiologic effects are observed after SNS activation. ${ }^{6}$ (1)

Norepinephrine (NE) released from neurons via the left stellate ganglions reaches the left ventricles, leading to an increase in contractile strength and blood pressure; NE released from neurons via the right stellate ganglion increases heart rate and shortens atrioventricular conduction via the sinus and atrioventricular nodes. (2) Epinephrine released into circulation by the adrenal cortex exerts effects on both the myocardium and peripheral vessels. (3) Locally released epinephrine and NE have direct effects on peripheral vessels. (4) Circulating norepinephrine acts in multiple locations, such as to increase heart rate during exercise of heart-transplant recipients who lack adrenergic innervation to the cardiac allograft.

\section{Receptors}

Norepinephrine and epinephrine released by components of the sympathetic nerve system bind to specific adrenergic receptors (ARs). All ARs are proteins embedded in the cell membrane with 7 transmembrane structures, coupling to heterotrimeric G proteins (Fig. 1). $\beta$-Receptor density displays a gradient, greatest at the apex and decreasing toward the base. There are a total of 9 different AR subtypes including 3 a1-receptors, 3 a2-receptors, and 3 $\beta$-receptors $(\beta 1, \beta 2$, and $\beta 3) .{ }^{7}$ The human heart contains mainly $\beta 1, \beta 2$, and $\beta 3$ receptors. ${ }^{7}$ Activation of $\beta 1$ - and $\beta 2$-ARs is the most powerful physiologic mechanism to acutely increase cardiac performance via positive inotropic, dromotropic, and chronotropic effects. $\beta 1$-ARs activate $G_{s}$ proteins, whereas $\beta 2$-ARs couple both $G_{i}$ and $G_{s}$ proteins. $G_{s}$ signaling acts as a "receptor accelerator" and $\mathrm{G}_{\mathrm{i}}$ signaling acts as a "receptor brake." 8 The human heart also expresses a 1-ARs at low levels (about 20\%), but its role in physiologic conditions is unknown. ${ }^{9}$

\section{REFLEX MECHANISM OF SYMPATHETIC HYPERACTIVITY IN HEART}

\section{FAILURE}

\section{Afferent Pathways}

Our present understanding of the complex mechanisms engaged by HF arises primarily from the application of NE kinetic methods, which quantify the spillover into plasma from total body, cardiac, renal, brain, or forearm NE production, and from microneurographic recordings obtained from sympathetic fibers innervating muscle or cutaneous vascular beds. 3,10,11 The latter technology refers to muscle sympathetic nerve activity (MSNA), which is a real-time measure of sympathetic nerve activity characterized by inserting a tungsten microelectrode into the muscle fascicle of the innervating peripheral nerve. Based on animal 
and human studies, the main reflex responses originate from the following afferent pathways (Fig. 2):

- $\quad$ Aortic arch and carotid baroreceptors (SNS inhibition)

- $\quad$ Cardiopulmonary baroreceptors (diverse reflexes including the Bezold-Jarisch reflex, SNS inhibition)

- Cardiovascular-low threshold polymodal receptors (SNS activation)

- $\quad$ Peripheral chemoreceptors (SNS activation) ${ }^{5}$

In systolic HF, SNS hyperactivity is closely related to abnormalities observed in the cardiovascular reflexes. ${ }^{1,3}$ The SNS inhibitory reflexes such as the arterial baroreceptor reflex are significantly suppressed, whereas the SNS excitatory reflexes such as the peripheral chemoreceptor reflex are augmented. ${ }^{12}$ In asymptomatic patients with left ventricular dysfunction, SNS activation precedes the development of symptoms and is related to poor survival. ${ }^{13}$ Of interest, decreased parasympathetic tone is noted to precede sympathetic activation in a canine model of nonischemic HF. ${ }^{14}$ It has long been considered that a generalized activation of the SNS in left ventricular systolic dysfunction leads to alterations of cardiac and peripheral hemodynamics, which are initially appropriate but eventually pathologic. ${ }^{15}$ However, the time course and magnitude of SNS activation are now recognized to be organ-specific and independent of ventricular systolic dysfunction. ${ }^{3}$

Obstructive sleep apnea-Among HF patients, approximately one-third have obstructive sleep apnea (OSA) and one-third have central sleep apnea. ${ }^{16}$ It has been demonstrated that each pause in breathing during sleep elicits profound increases in MSNA in humans with OSA. ${ }^{17}$ Compared with HF patients without sleep apnea, MSNA was 11 bursts per 100 heartbeats higher in those with existing OSA. ${ }^{18}$ In a subset study of a randomized controlled trial, MSNA in patients was decreased by 12 bursts per 100 heartbeats after they received successful continuous positive airway pressure therapy. ${ }^{19}$ These data have demonstrated that 2 independent sympathoexcitatory processes (HF and OSA) can increase MSNA via an additive summation effect. Sleep-related breathing disorders provide a potent stimulus for adrenergic upregulation.

Myocardial ischemia and infarction-One study followed patients with relatively preserved ejection fraction (mean 52\%) 6 months after myocardial infarction. These subjects were noted to have higher MSNA burst incidence in comparison with patients with coronary artery disease or healthy control subjects. ${ }^{20}$ Compared with patients with nonischemic cardiomyopathy and a low left ventricular ejection fraction, MSNA was significantly higher in those with ischemic cardiomyopathy. ${ }^{21}$ Myocardial ischemia and prior infarction have adverse effects on sympathetic outflow, both additive and independent of magnitude of ejection fraction. ${ }^{3}$

Reflex from skeletal muscle-Skeletal muscles have the capacity to increase the set point of central sympathetic outflow in HF at rest or during exercise. This reset can be achieved by an adenosine/angiotensin-mediated sympathoexcitatory reflex, activation of a 
muscle mechanoreflex elicited by passive exercise, or a muscle metaboreflex activated by handgrip. ${ }^{22-24}$

Renal failure-MSNA stimulation is noted in patients with chronic renal failure. ${ }^{25}$ Similar activation in milder renal insufficiency or the cardiorenal syndrome may lead to increased adrenergic stimulation.

\section{Efferent Pathways}

Coordination of sympathetic outflow from the brain begins in the dorsolateral reticular formation of the medulla, and is modulated by the hypothalamus. Two sets of motor neurons conduct signals to the periphery, preganglionic and postganglionic. The preganglionic fibers originate from the brainstem or the lateral horns of thoracolumbar spinal cord segments. These short, myelinated fibers use acetylcholine as a neurotransmitter, and synapse either with chromaffin cells in the adrenal medulla or with postganglionic fibers in either paravertebral or prevertebral (also known as preaortic) ganglia. These fibers travel along blood vessels in the periphery or in the heart. Norepinephrine is the principal neurotransmitter distally. NE uptake and release into the synaptic junction may be inhibited by presynaptic a2-receptor antagonists and increased by $\beta 2$-receptor stimulation with epinephrine. Terminal muscarinic receptors decrease NE secretion when stimulated by acetylcholine (Fig. 3). 1,3

\section{CENTRAL MECHANISM OF SYMPATHETIC HYPERACTIVITY IN HEART}

\section{FAILURE}

\section{Coupling of Renin-Angiotensin System and Reactive Oxidative Stress in Brain}

The renin-angiotensin system (RAS) is considered to be the main system of regulating SNS in the brain. ${ }^{26}$ The brain RAS system is activated in experimental chronic systolic HF with enhanced sympathetic outflow. ${ }^{27}$ Angiotensin II type 1 (AT1) receptors are expressed at high levels in areas of hypothalamus and medulla, which regulate sympathetic outflow. ${ }^{28}$ In addition, aldosterone can increase AT1 receptor levels in the paraventricular nucleus (PVN) of the hypothalamus. ${ }^{29}$ The mechanism of RAS causing sympathetic excitation is involved with brain reactive oxidative stress. It is well established that activation of the AT1 receptor can induce oxidative stress in the rostral ventrolateral medulla (RVLM), known as the vasomotor center. ${ }^{27}$ In animal models of chronic HF, microinjection of angiotensin II into the RVLM results in sympathoexcitation, whereas microinjection of AT1 receptor blockers into the RVLM causes sympathoinhibition. ${ }^{27}$

\section{Brain Inflammatory Mediators}

Nuclear factor $\kappa \mathrm{B}$ (NF- $\kappa \mathrm{B})$ exhibits cross-talk between proinflammatory cytokines and brain RAS in rats with chronic systolic $\mathrm{HF}^{30}$ Nitric oxide (NO) causes sympathoinhibition in the brain, probably through the mechanism of counteracting oxidative stress. ${ }^{31}$ Overexpression of NO synthase in the brain can attenuate abnormal sympathoexcitation in mice with HF. Of note, small G-protein Rho/Rho kinase pathway, mineralocorticoid 
receptors, Na sensitivity, or toll-like receptor 4 in the brain each can cause sympathoexcitation in a rat model of systolic HF.

In 2009, Floras ${ }^{3}$ proposed a new model of SNS activation in systolic HF that characterized a balance between normal compensatory reflexes and excessive responses in the setting of increased adrenergic output attributable to a higher central adrenergic set point (see Fig. 1). Critical components of this model included: (1) impaired vagally mediated arterial baroreceptor reflex regulation of heart rate; (2) MSNA regulated by an arterial baroreflex that rapidly responds to changes in diastolic blood pressure, modulates generalized sympathetic discharge, and responds to diminished pulsatile arterial mechanoreceptor stretch by adjusting, as required, a centrally established set point for sympathetic outflow; (3) pulmonary mechanoreceptor-mediated entrainment of sympathetic outflow; (4) blunted inhibitory ventricular baroreceptor reflex control of MSNA; and (5) increased cardiac norepinephrine spillover early in the course of HF caused by a cardiac-specific sympathoexcitatory reflex stimulated in the setting of elevated left ventricular diastolic filling pressures.

\section{EFFECT OF SYMPATHETIC HYPERACTIVITY ON HEART FAILURE}

\section{NE Spillover}

In systolic HF, sympathetic hyperactivity is evidenced by increased plasma NE levels, central sympathetic outflow, and NE plasma spillover from activated sympathetic nerve fibers. ${ }^{1}$ While NE clearance is reduced in patients with HF, it does not account for the increased NE measured. The use of isotope dilution methods to measure cardiac NE plasma release have indicated as much as a 50-fold increased cardiac NE spillover in untreated systolic HF. ${ }^{1}$ In addition, systolic HF patients may have decreased NE concentrations in the cardiomyocytes and/or reduced postsynaptic $\beta$-receptor density. ${ }^{1}$

\section{Cardiac Remodeling}

In HF, the cardiac neuronal hierarchy undergoes a pathologic remodeling process. Spatially organized reflexes acting in isolation may destabilize efferent neuronal control of regional cardiac mechanical and/or electrical events. ${ }^{1}$ For example, angiotensin II can initiate a positive feedback mechanism, leading to upregulated AT1 receptors, NO inhibition, and increasing oxidative stress by increased production of superoxide anion. ${ }^{32}$ This pathway can lead to further increases in sympathetic outflow and disease progression.

\section{Receptor Level Changes}

Prolonged SNS activation can adversely affect excitation-contraction coupling and enhance the apoptotic pathways, playing a central role in the disease progression of chronic $\mathrm{HF}^{33} \mathrm{~A}$ striking characteristic of $\mathrm{HF}$ is the set of molecular events in the $\beta$-AR signaling pathway, including a decrease in $\beta 1$-AR density, uncoupling of $\beta 1$-ARs from $G_{s}$, increased $G_{i}$ protein, and impaired compartmentalization of cyclic adenosine monophosphate/protein kinase $\mathrm{A}$ signaling. ${ }^{34}$ The role of $\beta 2$-AR in HF has not been described clearly. There is no significant change in the levels of $\beta 2$-ARs in the failing heart. ${ }^{35}$ The role of $\beta 3$-ARs in HF has not been elucidated. Recently it has been demonstrated that $\beta$-AR desensitization by tumor necrosis 
factor $\boldsymbol{a}$ is mediated by G-protein-coupled receptor kinase 2 and is agonist independent, suggesting a novel mechanism for inflammatory modulation of $\beta$-receptor response. ${ }^{36}$

Impact of $\beta$-Adrenergic Receptor Polymorphism

Marked variability in HF phenotype and response to therapy implies complex interactions of genetic variations and disease-modifying mechanisms. Polymorphisms in adrenergic receptor genes have been associated with variable clinical response to $\beta$-blocker therapy through the study of pharmacogenomics. A substudy of BEST (Beta Blocker Evaluation of Survival Trial), a bucindolol versus placebo HF trial, demonstrated drug response variability that was dependent on 2 coding AR polymorphisms: the Arg389Gly of the $\beta 1$-AR, and a position 322-325 4-amino-acid deletion (Del) in the prejunctional sympathetic nerve terminal a2C-AR. ${ }^{37}$ Subpopulations with enhanced ( $\beta(1) 389$ Arg homozygotes), intermediate $(\beta(1) 389$ Gly carriers $+\alpha(2 \mathrm{C}) 322-325 \mathrm{Wt}$ homozygotes), and no ( $\beta(1) 389$ Gly carriers $+a(2 C) 322-325$ Del carriers) efficacy were identified. ${ }^{38}$ A substudy of HFACTION (Heart Failure: A Controlled Trial Investigating Outcomes of Exercise TraiNing) patients with the ADR $\beta 1$-389 Arg/Arg genotype receiving low-dose $\beta$-blockers had a 2-fold increase in the risk of death compared with those receiving a high dose (hazard ratio 2.09; $P$ $=.015$ ), which was not conferred in Gly carriers. ${ }^{39}$ There was a gene-dose interaction with the ADR $\beta 1-389$ Arg/Arg versus Gly carrier genotype and $\beta$-blocker dose, suggesting that patients with the Arg/Arg genotype might require a higher dose of $\beta$-blockade to achieve a treatment response similar to that of Gly carriers.

\section{ROLE OF PARASYMPATHETIC DYSFUNCTION IN HEART FAILURE}

The sensory endings of both vagal and sympathetic afferent fibers in the heart are mechanoreceptors, thereby stimulated by the mechanical stretching associated with cardiac dilatation in HF. In HF with chamber dilatation, both vagal and sympathetic afferent cardiac fibers increase firing, as a result of which the afferent sympathetic excitation leads to tonic and reflex inhibition of cardiac vagal efferent activity. ${ }^{5}$ In cases of diastolic dysfunction with no dilatation of heart, the mechanism of reduced vagal activity has not been fully determined. ${ }^{15}$

\section{Translation into Heart Failure: Diagnostic Implications}

Two state-of-the-art techniques can be used to quantify sympathetic nerve activity with potential diagnostic values: the radiotracer measurement of regional NE spillover and microneurography (microelectrode direct measurement of postganglionic sympathetic nerve activity: the proximate neural stimulus to NE release).

Muscle sympathetic nerve activity-Excessive sympathetic activation under resting conditions has been shown to increase from the early stages of systolic HF, and is related to prognosis. Direct recording of multiunit efferent MSNA by microneurography is the best method for quantifying sympathetic nerve activity in humans. ${ }^{40}$ To date, this technique has been used to evaluate the actual central sympathetic outflow to the periphery in HF patients at rest and during exercise. However, because the firing occurrence of sympathetic activation is mainly synchronized by pulse pressure, multiunit MSNA, expressed as burst frequency 
(bursts/min) and burst incidence (bursts/ 100 heartbeats), may have limitations for the quantification of sympathetic nerve activity. ${ }^{40}$ In HF, multiunit MSNA is near the maximum level, and cannot increase more than the heartbeat. Although single-unit MSNA analysis in humans is technically demanding, it provides more detailed information regarding central sympathetic firing.

Nuclear imaging-Cardiac neuronal distribution and function can be imaged using radiolabeled analogues of $\mathrm{NE}$ with standard gamma cameras and positron emission tomography (PET). In addition, postsynaptic $\beta$-AR distribution and density can also be determined by PET. An analogue of NE, ${ }^{123}$ I-metaiodobenzylguanidine (MIBG), can be used to measure cardiac sympathetic neuronal activity noninvasively, as well as other semiquantitative parameters including early heart-to-mediastinum ratio, late heart-tomediastinum ratio, and myocardial washout. Decreased late heart-to-mediastinum ratio or increased myocardial MIBG washout is associated with a worse prognosis in comparison with those patients having normal myocardial MIBG parameters. ${ }^{41} \beta$-Blockade and reninangiotensin-aldosterone inhibition are associated with an increase in MIBG uptake and a reduced washout. ${ }^{1}$ The ADMIRE-HF (AdreView Myocardial Imaging for Risk Evaluation in Heart Failure) trial demonstrated that MIBG cardiac imaging can provide independent prognostic information for risk-stratifying patients with HF, in additional to commonly used markers such as left ventricular ejection fraction and B-type natriuretic pepetide. ${ }^{42}$ The survival data from 961 patients of NYHA class II to III in the ADMIRE-HF trial were analyzed using the Seattle Heart Failure Model (SHFM). The addition of MIBG imaging to the SHFM improves risk stratification, especially in higher-risk patients. MIBG may have clinical utility in higher-risk patients who are being considered for therapy such as implantable cardioverter-defibrillators, cardiac resynchronization devices, left ventricular assist devices (LVADs), and cardiac transplantation. ${ }^{43}$

Other measurements-The measurement of plasma NE can only be used as a crude guide to assess SNS activity, because it depends on the rate of immediate NE reuptake and NE clearance from circulation. ${ }^{1}$ Also, the technique for measuring serum levels is somewhat complicated. Nevertheless, elevated plasma NE levels have been correlated with NYHA functional capacity and prognosis in patients with left ventricular systolic HF. Heart-rate variability (HRV), an easily performed noninvasive methodology, does have prognostic significance (ie, decreased HRV is a negative prognosticator) but practical limitations, given that a high percentage of the HF subjects have atrial fibrillation, paced rhythm, or are diabetic (associated with autonomic dysfunction and decreased HRV). ${ }^{1}$

\title{
THE SYMPATHETIC NERVOUS SYSTEM IN HEART FAILURE: THERAPEUTIC IMPLICATIONS
}

\author{
$\beta$-Blockers
}

$\beta$-Blockers can be broadly classified into 3 generations based on receptor-level activity:

1. First generation, which are nonselective and competitively block both the $\beta 1$ and $\beta 2$-receptors (propranolol, nadolol, timolol) 
2. Second generation, with much higher affinity for the $\beta 1$ - than for the $\beta 2$-receptor (atenolol, metoprolol, bisoprolol)

3. Third generation, which may be selective (celiprolol, nebivolol) or nonselective (bucindolol, carvedilol, labetalol), but all causing peripheral vasodilatation mediated via either a1-receptor blockade (bucindolol, carvedilol, labetalol), $\beta 2$ receptor agonism (celiprolol), or NO synthesis (nebivolol). ${ }^{44}$

Among all $\beta$-blockers, bisoprolol (except in the United States), carvedilol, and metoprolol succinate (except in Canada) are almost universally approved for the treatment of chronic systolic HF (Table 1). ${ }^{1}$ Carvedilol was the first $\beta$-blocker with demonstrated efficacy in chronic systolic HF. The US Carvedilol Trials program demonstrated that administration of the $\beta$-blocker to a population of predominantly NYHA Class II and III patients who were stable on a background regimen of angiotensin-converting enzyme (ACE) inhibitors, diuretics, and digoxin reduced all-cause mortality by $65 \%$ and the risk of death or hospitalization for cardiovascular reasons by $35 \%$. Of note, the trial was stopped early by the trial's Data Safety and Monitoring Board because of the drug's observed favorable effect on mortality. ${ }^{45}$ The Carvedilol Prospective Randomized Cumulative Survival Study Group (COPERNICUS) Study in 1997 extended the evidence of efficacy to a sicker HF population, and included patients who were recently NYHA Class IV and hospitalized patients. ${ }^{46}$ Subsequently, similar beneficial results were observed with metoprolol succinate (Metoprolol CR/XL Randomized Intervention Trial in Congestive Heart Failure [MERIT$\mathrm{HF}]$ ) and bisoprolol (The Cardiac Insufficiency Bisoprolol Study II [CIBIS-II]). ${ }^{47,48}$ Clearly, however, not all $\beta$-blockers are efficacious in chronic HF. Bucindolol, a nonselective $\beta$ blocker with $\alpha$-blocking effects, failed to demonstrate a survival benefit, and metoprolol tartrate, a selective $\beta$-blocker, at a relatively low dose of $50 \mathrm{mg}$ twice daily, was inferior to carvedilol. ${ }^{49,50}$ Extensive clinical studies have established that chronic $\beta$-blocker therapy with carvedilol, metoprolol succinate, or bisoprolol improves left ventricular performance and reverses left ventricular remodeling, reduces the risk of hospitalization, and improves survival. ${ }^{1}$ However, the exact mechanism(s) for these laudatory effects are not clearly defined.

\section{a-Blockers}

As potent arteriolar vasodilators, this class of drugs was initially thought to have promise as HF therapy. Prazosin was compared with hydralazine and isosorbide dinitrate originally in the Veterans Administration Cooperative Study (V-HeFT). However, patients in the prazosin arm experienced worse outcomes than those receiving the combined vasodilator therapy of hydralazine and isosorbide dinitrate. ${ }^{51}$ The underlying mechanism for this observed adverse effect could be sympathetic upregulation as indicated by increased catecholamine levels after chronic use of prazosin, counteracting any potentially beneficial action mediated through inhibition of the a1-receptor. Later, in the ALLHAT (Antihypertensive and LipidLowering Treatment to Prevent Heart Attack Trial) study (ALLHAT collaborative), the study of another a 1-blocker, doxazosin, was terminated early because of a higher HF incidence in subjects taking the drug. ${ }^{15}$ 


\section{Centrally-Acting a2-Blockers}

In the past decade, more experiments have revealed that the central nervous system (CNS) plays a key role in the sympathoexcitation noted in HF. Thus, the central a2-receptor has been considered as a possible target in the treatment of HF, because excitation of the central a2-receptor inhibits the activation of the SNS. Clonidine displays a2-agonist actions in the CNS. At modest doses, clonidine significantly attenuates cardiac and renal sympathetic tone in patients with HF. ${ }^{15}$ Of interest, chronic clonidine administration exerted marked sympathoinhibitory effects without further clinical deterioration in a small, short-term clinical study. ${ }^{15}$ Large clinical trials will be needed to evaluate potential benefits. However, in clinical trials of the centrally acting sympathoinhibitory agent, moxonidine (which acts through both a2- and imidazoline receptors), the drug was associated with an increased mortality. ${ }^{15,36}$

\section{Renin-Angiotensin-Aldosterone Modulators}

Angiotensin II and aldosterone production enhance the release and inhibit the uptake of norepinephrine at nerve endings, and thus modulate the adrenergic response in the periphery.

${ }^{30}$ However, angiotensin and aldosterone also have targets of action centrally. High densities of AT1 receptors are present in brain regions both outside and inside the blood-brain barrier, thus providing a pathway whereby peripherally administered AT1 receptor blockers are able to exert centrally acting effects on sympathetic activity. Recent studies have suggested that systemically administered AT1 receptor blockers reduced blood pressure in hypertensive rats, by acting on CNS AT1 receptors. ${ }^{31}$ Plasma aldosterone levels may be elevated as high as 20 -fold in patients with HF, primarily because of increased production by the adrenal glands following stimulation by the high plasma angiotensin II concentrations. Two trials of aldosterone receptor blockers, RALES (Randomized Aldactone Evaluation Study) and EPHESUS (Eplerenone Post-Acute Myocardial Infarction Heart Failure Efficacy and Survival Study), demonstrated the benefit of aldosterone antagonists in HF patients. ${ }^{52,53}$ Data have shown that these drugs decrease central sympathetic activity in rats and improve norepinephrine uptake in humans with HF. ${ }^{15}$

\section{Digoxin}

Digoxin is considered the oldest HF therapy still in use. Its utility in HF has been debated, but best evidence suggests that it may be an effective agent for improving symptoms and reducing hospitalizations while having a neutral effect on mortality. Digoxin acts via several mechanisms that may be helpful for treating HF, the most commonly acknowledged of which is to increase inotropy by indirectly increasing intracellular calcium available to the sarcoplasmic reticulum. However, digoxin also modulates sympathetic outflow by improving baroreceptor function, decreasing sympathetic tone, and increasing sympathetic tone. ${ }^{54,55}$

\section{Exercise}

Exercise intolerance is a hallmark of patients with chronic HF, and skeletal myopathy contributes to the limitation of functional capacity. ${ }^{15}$ The activation of SNS and myogenic reflex engagement regulate the heart and muscle vasculature to maintain adequate blood 
pressure during exercise ${ }^{56}$ However, abnormal activation of the SNS contributes to the skeletal myopathy seen in HF, because SNS-mediated vasoconstriction at rest and during exercise restrains muscle blood flow, arteriolar dilation, and capillary recruitment, leading to underperfusion, ischemia, release of reactive oxygen species, and chronic inflammation. ${ }^{41}$ HF-ACTION, the first large, randomized controlled trial to evaluate the effects of exercise training in HF patients, demonstrated that exercise training was safe and offered clinical benefits, although it did not meet its primary end point and was considered a negative trial. ${ }^{43}$ Proposed mechanisms beneficial effects include: (1) improvement in arterial and chemoreflex control; (2) significant reduction in central sympathetic outflow; (3) correction of CNS abnormalities; (4) increase in peripheral blood flow; (5) reduction of circulating cytokines; and (6) increase in muscle mass. Experimental evidence suggests that the exercise training-induced beneficial effects on autonomic activity in HF may be due to an upregulation in central antioxidative mechanisms and suppressed central prooxidant mechanisms. ${ }^{15}$

\section{NOVEL THERAPIES AND FUTURE PERSPECTIVES}

\section{New Centrally Acting Medications}

Previous studies have shown AT1 receptor-induced oxidative stress in the brain, especially in the RVLM, to be a novel therapeutic target for chronic HF through the mechanism of SNS inhibition. ${ }^{27}$ Central administration of antisense oligonucleotides targeted against mRNA of the AT1 receptor in a rat model of ischemic HF reduced both the resting sympathetic tone and the sympathetic reflex response. ${ }^{57}$ Orally administered atorvastatin causes sympathoinhibition and improves baroreflex dysfunction through reduction of oxidative stress and upregulation of NO synthase in the brain of hypertensive rats. ${ }^{15}$ Further clinical trials are necessary to clarify whether statins would have favorable modulatory effects on SNS hyperactivity in human systolic HF.

Parasympathetic stimulation-Research on the therapeutic modulation of cardiac autonomic tone by electrical stimulation has yielded encouraging early clinical results. Vagal nerve stimulation has reduced the rates of morbidity and sudden death from HF therapeutic vagus nerve stimulation is limited by side effects of hypotension and bradycardia. ${ }^{58} \mathrm{Of}$ interest, the recent Systolic HF trial of treatment with the $\mathrm{I}_{f}$ inhibitor ivabradine (SHIFT) evaluated the effects of ivabradine, a selective inhibitor of the $\mathrm{I}_{f}$ current in the sinoatrial node, without inotropic effects. ${ }^{59}$ The results favored ivabradine over placebo regarding lower hospital admission rates due to HF. Sympathetic nerve stimulation implemented in the experiment may exacerbate the sympathetic-dominated autonomic imbalance. By contrast, concurrent stimulation of both sympathetic and parasympathetic cardiac nerves increases myocardial contractility without increasing heart rate. ${ }^{58}$

Renal sympathetic denervation-An ongoing trial of renal sympathetic denervation in patients with treatment-resistant hypertension (SIMPLICITY HTN) uses the strategy of sympathoinhibition to treat resistant hypertension via percutaneous renal sympathetic denervation. ${ }^{60}$ Renal afferent nerves project directly into many areas within the CNS, controlling the SNS outflow activity. ${ }^{61}$ Resistant hypertension with systolic HF was not an 
exclusion criterion for the SIMPLICITY trial. ${ }^{62}$ Thus, future data from SIMPLICITY (subsets with HF) may demonstrate whether renal nerve ablation is a novel therapy for chronic HF.

Combined SNS inhibition and stimulation-Clenbuterol is a $\beta$-blocker with combined $\beta 1$-inhibition/ $\beta 2$-stimulation effect, and has been proposed as a treatment modality to achieve sustained reversal of severe HF in select patients with LVADs. ${ }^{63}$ The rationale for this approach was based on experimental studies demonstrating that clenbuterol treatment, alone or in combination with mechanical unloading, improved left ventricular function at the whole-heart and cellular levels by affecting cell morphology, excitationcontraction coupling, and myofilament sensitivity to calcium. ${ }^{64}$ In a substantial proportion of patients with nonpulsatile LVADs, the use of a combination of mechanical and pharmacologic therapy with $\beta$-blockers, ACE inhibitors, or angiotensin receptor blockers, and selective aldosterone receptor antagonists and clenbuterol, resulted in sustained improvement in left ventricular function after removal of the LVAD. ${ }^{65}$

Future perspectives-The mechanisms by which autonomic nervous system dysfunction occurs in HF have not been fully elucidated. In particular, the central abnormalities need further determination in clinical and basic research. How does the brain "recognize" the condition of "HF"? What is the input into the brain, neuronal, or humoral factors? The answers to these questions promise to contribute to a novel concept for the treatment of HF: "the brain is a major target in the treatment of HF through sympathoinhibition."

\section{SPECIAL CATEGORIES IN HEART FAILURE}

\section{Diastolic Heart Failure}

There is limited information regarding chronic SNS activation in HF with preserved left ventricular ejection fraction (diastolic HF) ${ }^{66}$ However, the findings of a study by Grassi and colleagues ${ }^{67}$ indicate that in patients with hypertension, SNS hyperactivity (increased muscle sympathetic nerve traffic) may contribute to the development of left ventricular diastolic dysfunction and account for the increased cardiovascular risk.

\section{Left Ventricular Assist Devices}

LVADs are now widely accepted as an option for patients with advanced HF. Firstgeneration devices were pulsatile, but had poor longevity and durability. Newer-generation devices are nonpulsatile and more durable, but remain associated with an increased risk of stroke and infection. More importantly, little is understood about the physiologic effects of the chronic absence (or extreme reduction) of pulsatile flow in humans, especially on sympathetic activity. HF patients with continuous, nonpulsatile LVADs have marked sympathetic activation in comparison with healthy controls and patients with pulsatile devices, which at least in part is likely due to baroreceptor unloading. ${ }^{68}$ Such chronic sympathetic activation may contribute to or worsen end-organ diseases, and reduce the possibility of ventricular recovery. Strategies to provide some degree of arterial pulsatility, even in continuous-flow LVADs, may be necessary to achieve optimal outcomes in these patients. 


\section{Right Heart Failure}

There is lack of data evaluating the role of SNS activation in right HF. However, in patients with chronic renal failure, MSNA is stimulated by the afferent signals from the uremic kidney. ${ }^{25}$ This reflex may become functionally important in patients with renal failure or right HF.

\section{References}

1. Triposkiadis F, Karayannis G, Giamouzis G, et al. The sympathetic nervous system in heart failure: physiology, pathophysiology, and clinical implications. J Am Coll Cardiol. 2009; 54(19):1747-62. [PubMed: 19874988]

2. Cohn JN, Pfeffer MA, Rouleau J, et al. Adverse mortality effect of central sympathetic inhibition with sustained-release moxonidine in patients with heart failure (MOXCON). Eur J Heart Fail. 2003; 5(5):659-67. [PubMed: 14607206]

3. Floras JS. Sympathetic nervous system activation in human heart failure: clinical implications of an updated model. J Am Coll Cardiol. 2009; 54(5):375-85. [PubMed: 19628111]

4. Schwartz PJ. Vagal stimulation for heart diseases: from animals to men. An example of translational cardiology. Circ J. 2011; 75(1):20-7. [PubMed: 21127379]

5. Schwartz PJ, De Ferrari GM. Sympathetic-parasympathetic interaction in health and disease: abnormalities and relevance in heart failure. Heart Fail Rev. 2011; 16(2):101-7. [PubMed: 20577900]

6. Van Stee EW. Autonomic innervation of the heart. Environ Health Perspect. 1978; 26:151-8. [PubMed: 363413]

7. Bylund, D., Bond, R., Clarke, D., et al. Adrenoceptors. In: Gidlestone, editor. The IUPHAR compendium of receptor characterization and classification. London: IUPHAR Media; 1998. p. 58-74.

8. Feldman DS, Elton TS, Benjmin S, et al. Mechanisms of disease: beta-adrenergic receptorsalterations in signal transduction and pharmacogenomics in heart failure. Nat Clin Pract Cardiovasc Med. 2005; 2(9):475-83. [PubMed: 16265588]

9. Woodcock EA, Du XJ, Reichelt ME, et al. Cardiac alpha 1-adrenergic drive in pathological remodelling. Cardiovasc Res. 2008; 77(3):452-62. [PubMed: 18032391]

10. Al-Hesayen A, Parker JD. Impaired baroreceptor control of renal sympathetic activity in human chronic heart failure. Circulation. 2004; 109(23):2862-5. [PubMed: 15173026]

11. Vallbo AB, Hagbarth KE, Wallin BG. Microneurography: how the technique developed and its role in the investigation of the sympathetic nervous system. J Appl Physiol. 2004; 96(4):1262-9. [PubMed: 15016790]

12. Watson AM, Hood SG, May CN. Mechanisms of sympathetic activation in heart failure. Clin Exp Pharmacol Physiol. 2006; 33(12):1269-74. [PubMed: 17184514]

13. Francis GS, Goldsmith SR, Levine TB, et al. The neurohumoral axis in congestive heart failure. Ann Intern Med. 1984; 101:370-7. [PubMed: 6147109]

14. Ishise $\mathrm{H}$, Asanoi $\mathrm{H}$, Ishizaka $\mathrm{S}$, et al. Time course of sympathovagal imbalance and left ventricular dysfunction in conscious dogs with heart failure. J Appl Physiol. 1998; 84(4):1234-41. [PubMed: 9516189]

15. Kishi T. Heart failure as an autonomic nervous system dysfunction. J Cardiol. 2012; 59(2):117-22. [PubMed: 22341431]

16. Wang H, Parker JD, Newton GE, et al. Influence of obstructive sleep apnea on mortality in patients with heart failure. J Am Coll Cardiol. 2007; 49(15):1625-31. [PubMed: 17433953]

17. Somers VK, Dyken ME, Clary MP, et al. Sympathetic neural mechanisms in obstructive sleep apnea. J Clin Invest. 1995; 96(4):1897-904. [PubMed: 7560081]

18. Spaak J, Eqri ZJ, Kubo T, et al. Muscle sympathetic nerve activity during wakefulness in heart failure patients with and without sleep apnea. Hypertension. 2005; 46(6):1327-32. [PubMed: 16286569] 
19. Usui K, Douglas BT, Jonas S, et al. Inhibition of awake sympathetic nerve activity of heart failure patients with obstructive sleep apnea by nocturnal continuous positive airway pressure. J Am Coll Cardiol. 2005; 45(12):2008-11. [PubMed: 15963401]

20. Graham LN, Smith PA, Stoker JB, et al. Time course of sympathetic neural hyperactivity after uncomplicated acute myocardial infarction. Circulation. 2002; 106(7):793-7. [PubMed: 12176949]

21. Notarius CF, Spaak J, Morris BL, et al. Comparison of muscle sympathetic activity in ischemic and nonischemic heart failure. J Card Fail. 2007; 13(6):470-5. [PubMed: 17675061]

22. Middlekauff HR, Chiu J, Hamilton MA, et al. Muscle mechanoreceptor sensitivity in heart failure. Am J Physiol Heart Circ Physiol. 2004; 287(5):H1937-43. [PubMed: 15475527]

23. Notarius CF, Atchison DJ, Rongen GA, et al. Effect of adenosine receptor blockade with caffeine on sympathetic response to handgrip exercise in heart failure. Am J Physiol Heart Circ Physiol. 2001; 281(3):H1312-8. [PubMed: 11514302]

24. Rongen GA, Lambrou G, Smits P, et al. Angiotensin AT1 receptor blockade abolishes the reflex sympathoexcitatory response to adenosine. J Clin Invest. 1998; 101:769-76. [PubMed: 9466971]

25. Hausberg M, Kosch M, Harmelink P, et al. Sympathetic nerve activity in end-stage renal disease. Circulation. 2002; 106(15):1974-9. [PubMed: 12370222]

26. Jankowska EA, Ponikowski P, Piepoli MF, et al. Autonomic imbalance and immune activation in chronic heart failure—pathophysiological links. Cardiovasc Res. 2006; 70(3):434-45. [PubMed: 16480965]

27. Zucker IH, Schultz HD, Patel KP, et al. Regulation of central angiotensin type 1 receptors and sympathetic outflow in heart failure. Am J Physiol Heart Circ Physiol. 2009; 297(5):H1557-66. [PubMed: 19717736]

28. Fisher JP, Young CN, Fadel PJ. Central sympathetic overactivity: maladies and mechanisms. Auton Neurosci. 2009; 148(1-2):5-15. [PubMed: 19268634]

29. Huang BS, Zheng H, Tan J, et al. Regulation of hypothalamic renin-angiotensin system and oxidative stress by aldosterone. Exp Physiol. 2011; 96(10):1028-38. [PubMed: 21824999]

30. Kang YM, Ma Y, Elks C, et al. Cross-talk between cytokines and renin-angiotensin in hypothalamic paraventricular nucleus in heart failure: role of nuclear factor-kappaB. Cardiovasc Res. 2008; 79(4):671-8. [PubMed: 18469338]

31. Hirooka Y, Sagara Y, Kishi T, et al. Oxidative stress and central cardiovascular regulation. Pathogenesis of hypertension and therapeutic aspects. Circ J. 2010; 74(5):827-35. [PubMed: 20424336]

32. Garrido AM, Griendling KK. NADPH oxidases and angiotensin II receptor signaling. Mol Cell Endocrinol. 2009; 302(2):148-58. [PubMed: 19059306]

33. Piacentino V 3rd, Weber CR, Chen X, et al. Cellular basis of abnormal calcium transients of failing human ventricular myocytes. Circ Res. 2003; 92(6):651-8. [PubMed: 12600875]

34. Dodge-Kafka KL, Soughaver J, Pare GC, et al. The protein kinase A anchoring protein mAKAP coordinates two integrated cAMP effector pathways. Nature. 2005; 437(7058):574-8. [PubMed: 16177794]

35. Liggett SB, Tepe NM, Lorenz JN, et al. Early and delayed consequences of beta(2)-adrenergic receptor overexpression in mouse hearts: critical role for expression level. Circulation. 2000; 101(14):1707-14. [PubMed: 10758054]

36. Vasudevan NT, Mohan ML, Gupta MK, et al. G $\beta \gamma$-independent recruitment of G-protein coupled receptor kinase 2 drives tumor necrosis factor $\alpha$-induced cardiac $\beta$-adrenergic receptor dysfunction. Circulation. 2013; 128(4):377-87. [PubMed: 23785004]

37. O'Connor CM, Anand I, Fiuzat M. Additive effects of beta-1 389 Arg/Gly and alpha-2c 322-325 wild-type/del genotype combinations on adjudicated hospitalizations and death in the Beta Blocker Evaluation of Survival Trial (BEST). J Card Fail. 2008; 14:S69.

38. O'Connor CM, Fiuzat M, Carson PE, et al. Combinatorial pharmacogenetic interactions of bucindolol and $\beta 1$, a2C adrenergic receptor polymorphisms. PLoS One. 2012; 7(10):e44324. [PubMed: 23071495] 
39. Fiuzat M, Neely ML, Starr AZ, et al. Association between adrenergic receptor genotypes and betablocker dose in heart failure patients: analysis from the HF-Action DNA substudy. Eur J Heart Fail. 2013; 15(3):258-66. [PubMed: 23115322]

40. Murai H, Takamura M, Kaneko S. Advantage of recording single-unit muscle sympathetic nerve activity in heart failure. Front Physiol. 2012; 3:109. [PubMed: 22563318]

41. Verberne HJ, Brewster LM, Somsen GA, et al. Prognostic value of myocardial ${ }^{123} \mathrm{I}$ metaiodobenzylguanidine (MIBG) parameters in patients with heart failure: a systematic review. Eur Heart J. 2008; 29(9):1147-59. [PubMed: 18349024]

42. Jacobson AF, Lombard J, Banerjee G, et al. ${ }^{123}$ I-mIBG scintigraphy to predict risk for adverse cardiac outcomes in heart failure patients: design of two prospective multicenter international trials. J Nucl Cardiol. 2009; 16(1):113-21. [PubMed: 19152136]

43. Ketchum ES, Jacobcon AF, Caldwell JH, et al. Selective improvement in Seattle Heart Failure Model risk stratification using iodine-123 meta-iodobenzylguanidine imaging. J Nucl Cardiol. 2012; 19(5):1007-16. [PubMed: 22949270]

44. Lopez-Sendon J, Swedberg K, McMurray J, et al. Expert consensus document on beta-adrenergic receptor blockers. Eur Heart J. 2004; 25(15):1341-62. [PubMed: 15288162]

45. Packer M, Bristow MR, Cohn JN, et al. The effect of carvedilol on morbidity and mortality in patients with chronic heart failure. U.S. Carvedilol Heart Failure Study Group. N Engl J Med. 1996; 334(21):1349-55. [PubMed: 8614419]

46. Packer M, Coats A, Fowler MB, et al. Effect of carvedilol on survival in severe chronic heart failure. N Engl J Med. 2001; 344(22):1651-8. [PubMed: 11386263]

47. Failure (MERIT-HF). Lancet. 1999; 353(9169):2001-7. [PubMed: 10376614]

48. Study II. (CIBIS-II): a randomised trial. Lancet. 1999; 353(9146):9-13. [PubMed: 10023943]

49. Beta-Blocker Evaluation of Survival Trial Investigators. A trial of the beta-blocker bucindolol in patients with advanced chronic heart failure. N Engl J Med. 2001; 344(22):1659-67. [PubMed: 11386264]

50. Poole-Wilson PA, Swedberg K, Cleland JG, et al. Comparison of carvedilol and metoprolol on clinical outcomes in patients with chronic heart failure in the Carvedilol Or Metoprolol European Trial (COMET): randomised controlled trial. Lancet. 2003; 362(9377):7-13. [PubMed: 12853193]

51. Cohn JN, Archibald DG, Ziesche S, et al. Effect of vasodilator therapy on mortality in chronic congestive heart failure. RESults of a Veterans Administration Cooperative Study. N Engl J Med. 1886; 314(24):1547-52.

52. Pitt B, Zannad F, Remme WJ, et al. The effect of spironolactone on morbidity and mortality in patients with severe heart failure. Randomized Aldactone Evaluation Study Investigators. N Engl J Med. 1999; 341(10):709-17. [PubMed: 10471456]

53. Pitt B, Remme W, Zannad F. Eplerenone, a selective aldosterone blocker, in patients with left ventricular dysfunction after myocardial infarction. N Engl J Med. 2003; 348(14):1309-21. [PubMed: 12668699]

54. Thames MD, Miller BD, Abboud FM. Sensitization of vagal cardiopulmonary baroreflex by chronic digoxin. Am J Physiol. 1982; 243(5):H815-8. [PubMed: 7137374]

55. Ferguson DW, Berg WJ, Sanders JS, et al. Sympathoinhibitory responses to digitalis glycosides in heart failure patients. Direct evidence from sympathetic neural recordings. Circulation. 1989; 80(1):65-77. [PubMed: 2736756]

56. Khan MH, Sinoway LI. Muscle reflex control of sympathetic nerve activity in heart failure: the role of exercise conditioning. Heart Fail Rev. 2000; 5(1):87-100. [PubMed: 16228918]

57. Zhu GQ, Gao L, Li Y, et al. AT1 receptor mRNA antisense normalizes enhanced cardiac sympathetic afferent reflex in rats with chronic heart failure. Am J Physiol Heart Circ Physiol. 2004; 287(4):H1828-35. [PubMed: 15371269]

58. Kobayashi M, Sakurai S, Takaseva T, et al. Effect of epivascular cardiac autonomic nerve stimulation on cardiac function. Ann Thorac Surg. 2012; 94(4):1150-6. [PubMed: 22939448]

59. Swedberg K, Komajda M, Bohm M, et al. Ivabradine and outcomes in chronic heart failure (SHIFT): a randomised placebo-controlled study. Lancet. 2010; 376(9744):875-85. [PubMed: 20801500] 
60. Esler MD, Krum H, Schlaich M, et al. Renal sympathetic denervation for treatment of drugresistant hypertension: one-year results from the Symplicity HTN-2 randomized, controlled trial. Circulation. 2012; 126(25):2976-82. [PubMed: 23248063]

61. DiBona GF, Esler M. Translational medicine: the antihypertensive effect of renal denervation. Am J Physiol Regul Integr Comp Physiol. 2010; 298(2):R245-53. [PubMed: 19955493]

62. Krum H, Schlaich M, Whitbourn R, et al. Catheter-based renal sympathetic denervation for resistant hypertension: a multicentre safety and proof-of-principle cohort study. Lancet. 2009; 373(9671):1275-81. [PubMed: 19332353]

63. Birks EJ, Tansley PD, Hardy J, et al. Left ventricular assist device and drug therapy for the reversal of heart failure. N Engl J Med. 2006; 355(18):1873-84. [PubMed: 17079761]

64. Soppa GK, Lee J, Staqq MA, et al. Role and possible mechanisms of clenbuterol in enhancing reverse remodelling during mechanical unloading in murine heart failure. Cardiovasc Res. 2008; 77(4):695-706. [PubMed: 18178572]

65. Birks EJ, George RS, Hedqer M, et al. Reversal of severe heart failure with a continuous-flow left ventricular assist device and pharmacological therapy: a prospective study. Circulation. 2011; 123(4):381-90. [PubMed: 21242487]

66. Hogg K, McMurray J. Neurohumoral pathways in heart failure with preserved systolic function. Prog Cardiovasc Dis. 2005; 47(6):357-66. [PubMed: 16115515]

67. Grassi G, Seravalle G, Quarti-Trevano F, et al. Sympathetic and baroreflex cardiovascular control in hypertension-related left ventricular dysfunction. Hypertension. 2009; 53(2):205-9. [PubMed: 19124679]

68. Markham DW, Fu Q, Palmer MD, et al. Sympathetic neural and hemodynamic responses to upright tilt in patients with pulsatile and nonpulsatile left ventricular assist devices. Circ Heart Fail. 2013; 6(2):293-9. [PubMed: 23250982] 


\section{KEY POINTS}

- Heart failure is a syndrome characterized by upregulation of the sympathetic nervous system and abnormal responsiveness of the parasympathetic nervous system.

- $\quad$ Hyperactivity of the sympathetic nervous system is triggered by both central and peripheral pathways that are associated with abnormal cardiovascular reflexes observed in a variety of disease states such as cardiac ischemia, ventricular dysfunction, renal failure, and obstructive sleep apnea.

- The renin-angiotensin aldosterone axis is the major regulator of the sympathetic nervous system in the brain.

- Sympathetic hyperactivity in heart failure leads to specific adverse effects which worsen the disease process including adverse remodeling, alteration of the beta adrenergic receptor system, and skeletal muscle abnormalities.

- The parasympathetic nervous system is also altered in heart failure with resulting adverse effects. 
Diagram of the adrenergic synapse

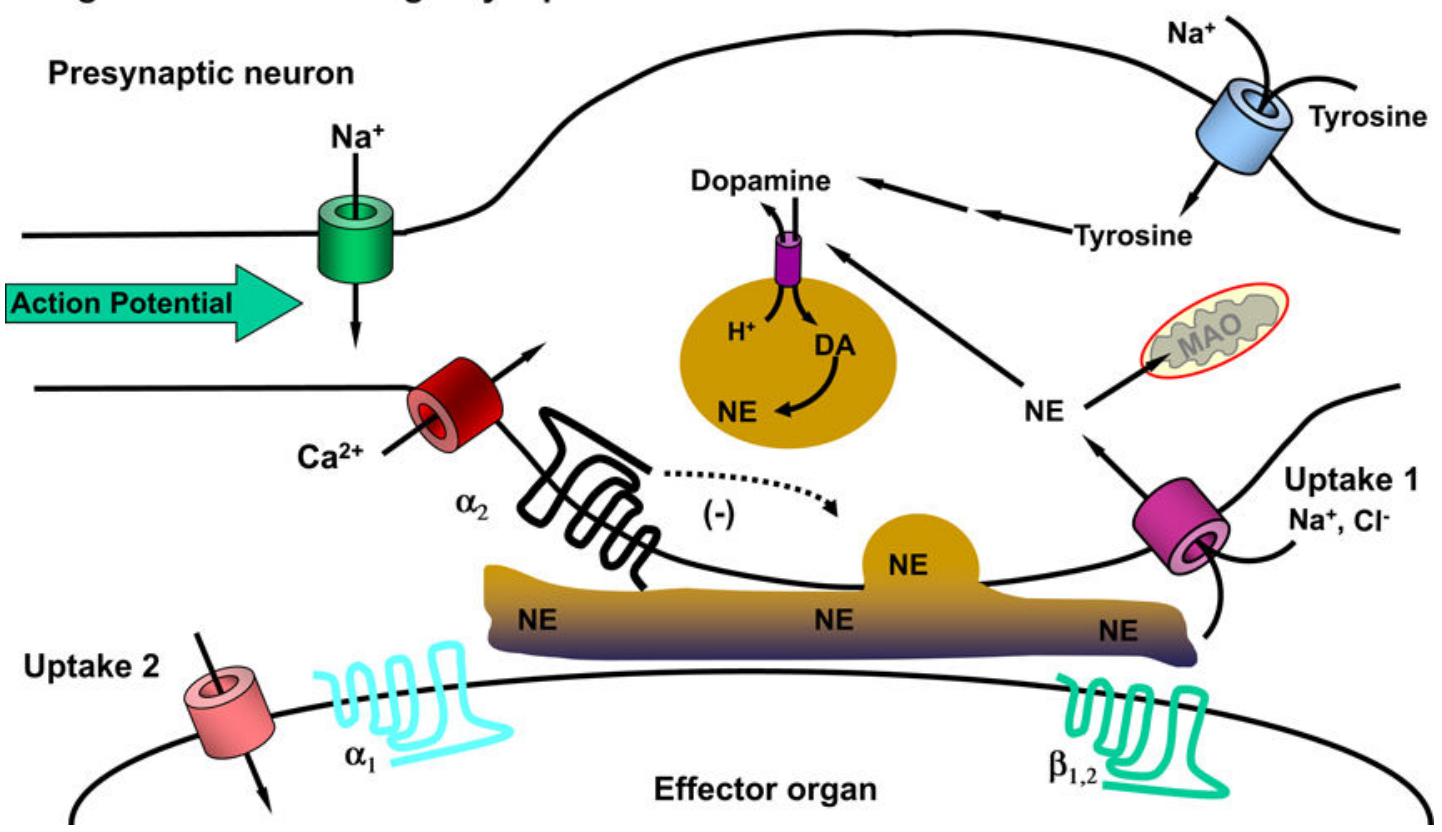

Fig. 1.

$\beta$-Receptors are G-protein-coupled receptors, and they act by activating a $G_{s}$ protein. $G_{s}$ activates adenylyl cyclase, leading to an increase in levels of intracellular cyclic adenosine monophosphate (cAMP). Increased cAMP activates protein kinase A, which phosphorylates cellular proteins. ATP, adenosine triphosphate. 


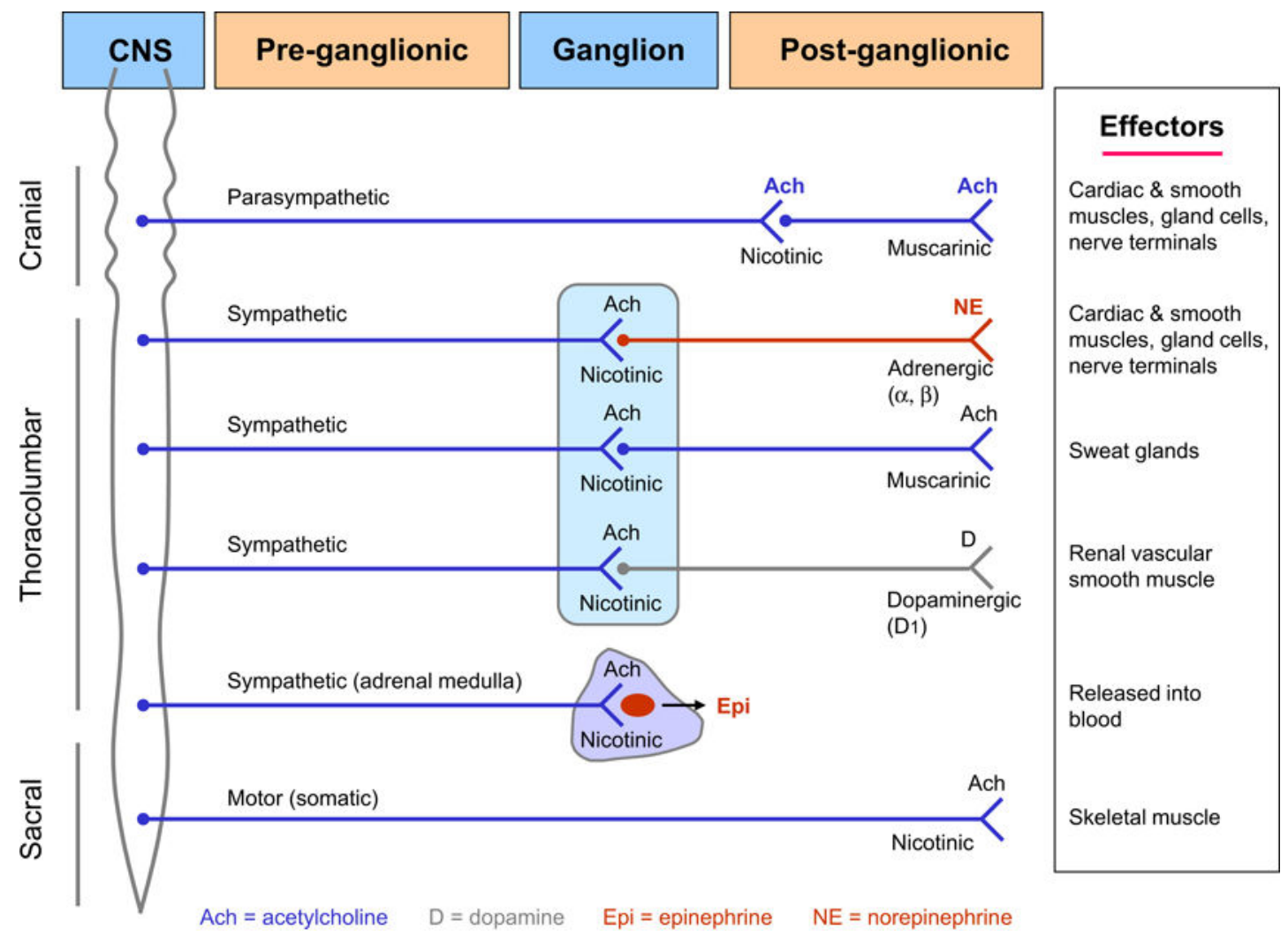

Fig. 2.

Summary of sympathetic and parasympathetic autonomic neural outflows from the central nervous system (CNS) that regulate the cardiovascular system. There are 2 major sets of neurons serially connected to regulate peripheral target organs controlled by the motor outflow of the sympathetic nervous system. The first set, called preganglionic neurons, originates in the brainstem or the spinal cord. The postganglionic neurons are the second set, located in a group of nerve cells called sympathetic ganglia outside the central nervous system. The predominant neurotransmitter of the sympathetic preganglionic neurons is acetylcholine. On the other hand, the predominant neurotransmitter of most sympathetic postganglionic neurons is norepinephrine, with exceptions such as postganglionic neurons innervating sweat glands by releasing acetylcholine. (Adapted from Johnston TB, Whillis J. Gray's anatomy. 31st edition. London: Longmans; 1954.) 


\section{Structure of adrenergic receptors:} $\beta$ receptors

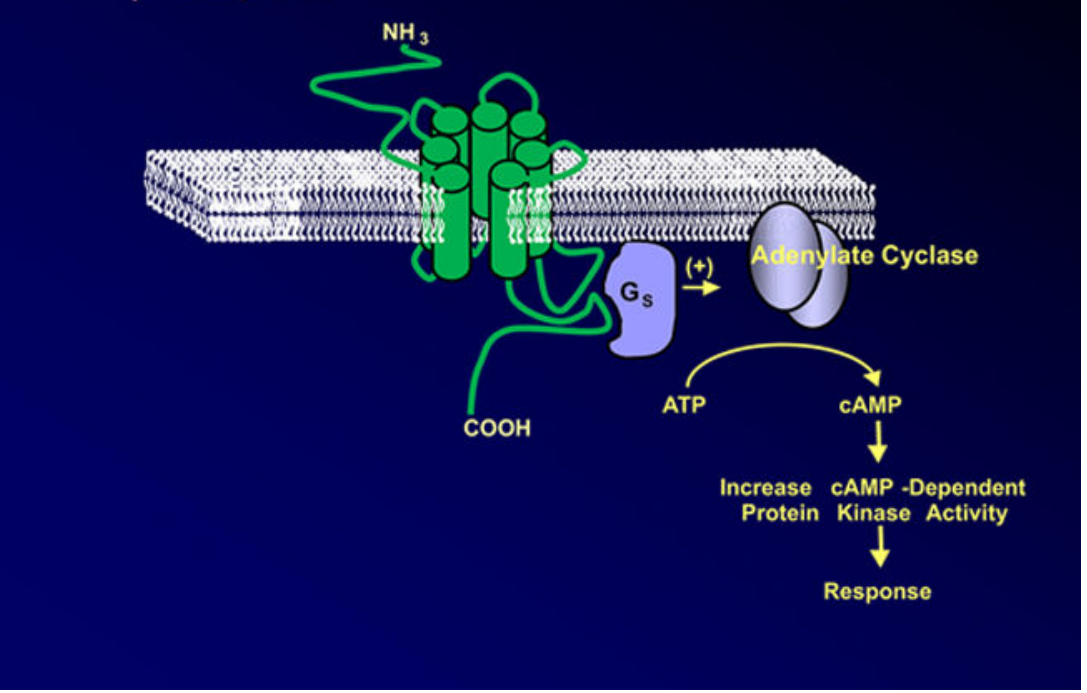

Fig. 3.

Adrenergic receptors and norepinephrine (NE) transport in the cardiac presynaptic nerve terminal. Thick solid black arrows indicate processes that facilitate NE transport to and from the synaptic cleft. Dashed black arrow shows negative feedback mechanisms that affect secretion. NE is stored within vesicles at the sympathetic nerve terminal. Sympathetic nerve activity results in release of $\mathrm{NE}$ from the storage vesicles in the synaptic cleft, where it is available to attach to postsynaptic a $1-, \beta 1-$, and $\beta 2$-adrenergic receptors, as well as presynaptic adrenergic receptors. In addition to these postsynaptic adrenergic receptors, there are presynaptic a 2-adrenergic receptors located on the sympathetic nerve terminal. Activation of the a 2 presynaptic receptor by an agonist reduces release of NE from the sympathetic nerve terminal, decreasing NE in the cleft and decreasing adrenergic activation of the cardiomyocyte. MAO, monoamine oxidase. 


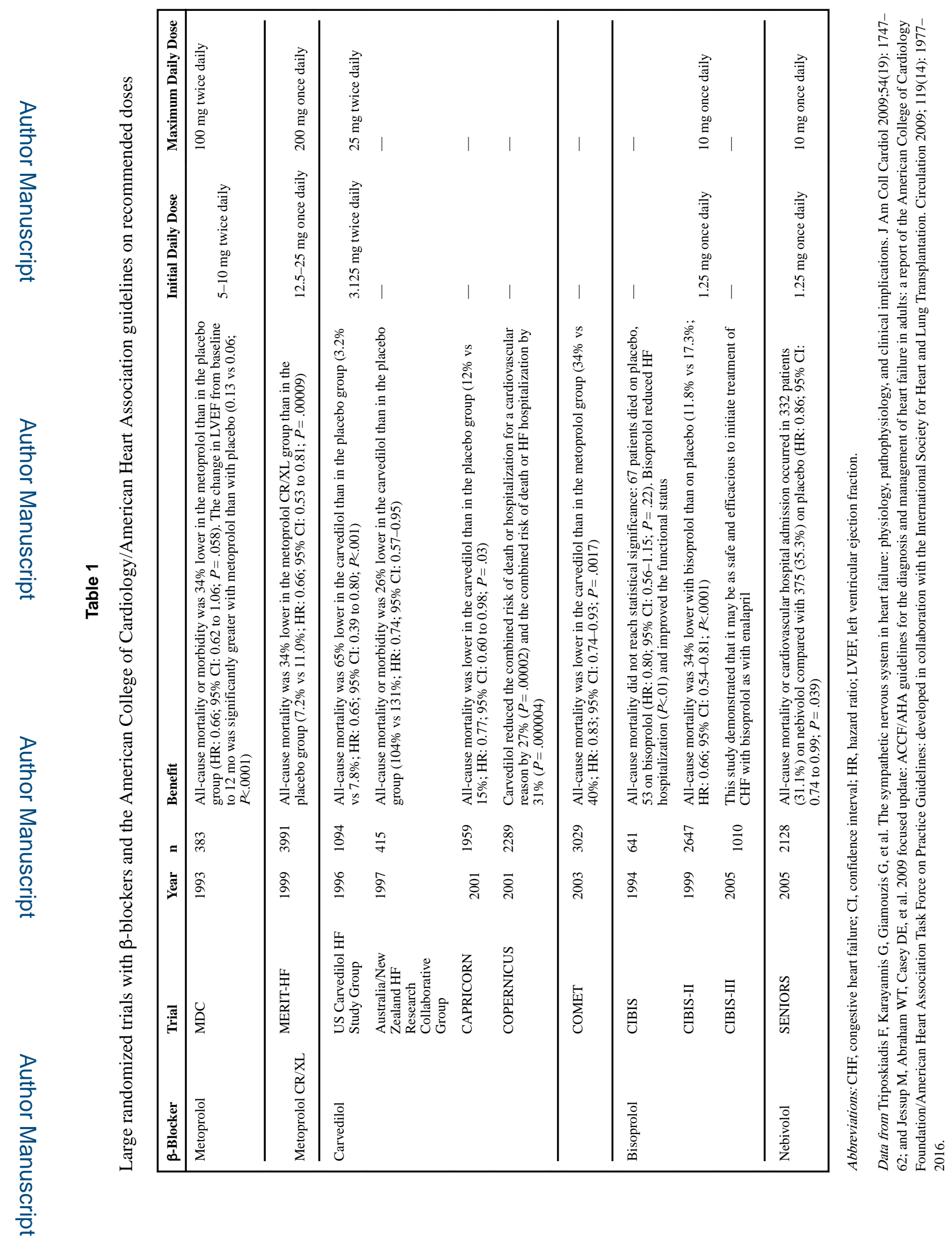

Cardiol Clin. Author manuscript; available in PMC 2018 March 28. 